\title{
Fixed Dose Rate versus Standard Dose Rate Infusion of Gemcitabine and Cisplatin in Advanced Stage Non-Small Cell Lung Cancer
}

\author{
Dina A. Salem, Dina R. Ibrahim*, Ahmed Ezzat, Azza M. Adel \\ Department of Clinical Oncology and Nuclear Medicine, Faculty of Medicine, Ain-Shams University, Cairo, \\ Egypt \\ Email: diabdina@hotmail.com
}

Received 19 November 2014; revised 20 December 2014; accepted 31 December 2014

Academic Editor: Fumihiko Hirai, National Kyushu Cancer Center, Japan

Copyright (C) 2015 by authors and Scientific Research Publishing Inc.

This work is licensed under the Creative Commons Attribution International License (CC BY).

http://creativecommons.org/licenses/by/4.0/

(c) (i) Open Access

\begin{abstract}
Background: Comparing the efficacy and safety of gemcitabine at a fixed-dose rate (FDR) infusion $\left(10 \mathrm{mg} / \mathrm{m}^{2} / \mathrm{min}\right)$ with the standard dose rate infusion in patients with locally advanced and metastatic non-small squamous cell carcinoma (NSCLC). Methods: The study randomized 60 patients with confirmed diagnosis of NSCLC to receive gemcitabine at a dose of $1000 \mathrm{mg} / \mathrm{m}^{2}$ on days 1 and 8 given as a 30-min infusion (Arm A) or at a rate of $10 \mathrm{mg} / \mathrm{m}^{2} / \mathrm{min}$ (Arm B). Cisplatin $75 \mathrm{mg} / \mathrm{m}^{2}$ was administered intravenously on day 2 in both arms. Results: No difference in overall response rate (46.6\% versus 43.3\%). Median time to progression for Arm A was 7 months (95\% CI, 6.207 - 7.793 months), versus 6 months for Arm B (95\% CI, 4.990 - 7.010 months). Median survival time was comparable [12 months (95\% CI, 8.588 - 15.412 months) versus 11 months (95\% CI, 9.066 12.934 months $)]$ respectively. Two-year survival $(18 \%$ versus $11 \%, p=0.38)$ was detected. No treatment related deaths occurred. Main hematological toxicities were grade I and II neutropenia, in $36.7 \%$ and $53.3 \%$ respectively $(p=0.044)$. Grade III anemia was observed in $10 \%$ and $6.7 \%$ in both arms respectively $(p=0.024)$. Grade I and II nausea and vomiting was observed in $50 \%$ and 46.7\%. Conclusions: FDR gemcitabine in combination with cisplatin had equivalent efficacy and more severe hematologic toxicities compared to the standard 30-min gemcitabine infusion with cisplatin in patients with advanced NSCLC.
\end{abstract}

\section{Keywords}

Non-Small Cell Lung Cancer, Gemcitabine, Fixed-Dose Rate, Toxicities

\footnotetext{
${ }^{*}$ Corresponding author.

How to cite this paper: Salem, D.A., Ibrahim, D.R., Ezzat, A. and Adel, A.M. (2015) Fixed Dose Rate versus Standard Dose Rate Infusion of Gemcitabine and Cisplatin in Advanced Stage Non-Small Cell Lung Cancer. Journal of Cancer Therapy, 6, 45-52. http://dx.doi.org/10.4236/jct.2015.61007
} 


\section{Introduction}

Lung cancer is the leading cause of cancer death in the United States. An estimated 226,000 new cases of lung and bronchus cancer will be diagnosed in 2012, and 160,000 deaths are estimated to occur due to the disease [1]. In Egypt, lung cancer is the sixth most common cancer, accounting for about $5 \%$ of all new cases. It is the fourth most common malignancy in males (7.5\%) and the ninth among females (2.3\%) [2].

Advanced Non-Small Cell Lung Cancer (NSCLC) encompasses metastatic disease (Stage IV) as well as locally advanced disease (Stage IIIB) that due to tumor or patient characteristics cannot be approached with curative intent [3]. Chemotherapy is the main treatment for patients with advanced NSCLC as it improves survival according to a meta-analysis based on individual patient data [4]. Among numerous chemotherapy regime ns, gemcitabine and cisplatin combination have been proved effective and tolerable [5].

Gemcitabine is taken up into the cell via human nucleoside transporters (hNTs) and is intracellulary phosphorylated by deoxycytidi ne kinase (dCK) to its monophosphate and subsequently into its main active triphosphate metabolite 2', 2'-difluorodeoxycytidine triphosphate (dFdCTP), which is incorporated into DNA and inhibits DNA synthesis. In addition, gemcitabine is extensively deaminated to 2', 2'-difuorodeoxyuridine, which is largely excreted into the urine [6].

Prolonged infusion of gemcitabine at a fixed dose rate (FDR) of $10 \mathrm{mg} / \mathrm{m}^{2}$ per minute was associated with a higher intracellular accumulation of dFdCTP, and a higher response rate than with the standard 30-minute infusion of gemcitabine. The explanation for this phenomenon lies in the saturation of deoxycytidine kinase which occurs after short infusion at conventional doses. This enzyme is needed to convert gemcitabine into its active form gemcitabine triphosphate. While short infusion leaves most of the drug unmetabolized, prolonged infusion results in a higher intracellular concentration of the active metabolite, thus enhancing the e agent's efficacy [7]. The improved survival in patients with pancreatic adenocarcinoma, who received FDR infusion in a randomized phase II clinical trial [8], encouraged many researchers to investigate the feasibility and efficacy of FDR gemcitabine in NSCLC patients [9]-[14]. However, controversial results have been drawn from these trials.

In light of this information, we conducted this phase III prospective clinical trial to compare the efficacy and safety of FDR infusion ( $10 \mathrm{mg} / \mathrm{m}^{2} / \mathrm{min}$ ) with the standard dose rate infusion of gemcitabine in patients with locally advanced and metastatic NSCLC.

\section{Material and Methods}

\subsection{Eligibility Criteria}

Chemonaive patients with histologically or cytologically confirmed locally advanced or metastatic stage IIIB or IV NSCLC according to the American Joint Committee on Cancer staging system (AJCC, 2002) [3], who were not amenable to surgery or radiation therapy with curative intent , were eligible for this study. Other eligibility criteria included the presence of at least one bi-dimensionally measurable lesion; at least 18 years old but not more than 60 years, Eastern Cooperative Oncology Group performance status (ECOG-PS) $\leq 2$; life expectancy $\geq$ 3 months; adequate bone marrow function (absolute neutrophil count $\geq 1.5 \times 10^{3} / \mathrm{ml}$, platelet count $\geq 100 \times$ $10^{3} / \mathrm{ml}$, hemoglobin $\geq 10 \mathrm{~g} / \mathrm{dL}$ ); adequate renal and hepatic function (serum creatinine $\leq 2 \mathrm{mg} / \mathrm{dl}$, hepatic enzymes $\leq 2.5 \times$ upper normal limit, bilirubin $\leq 2 \mathrm{mg} / \mathrm{dl}$ ). Exclusion criteria were brain metastases, other malignant diseases except for carcinoma of the cervix uteri in situ and squamous cell carcinoma of the skin, severe hepatic or renal impairment, and active infections or other severe co-morbid diseases that could have interfered with the trial. Written informed consent was obtained from all patients. The trial was approved by the Ethics and Scientific Committees at Faculty of Medicine, Ain-Shams University.

\subsection{Treatment Protocol}

Eligible patients were randomly assigned to receive gemcitabine at a dose of $1000 \mathrm{mg} / \mathrm{m}^{2}$ on days 1 and 8 given as a 30-min infusion (Arm A) or at a rate of $10 \mathrm{mg} / \mathrm{m}^{2} / \mathrm{min}$ (Arm B). Cisplatin $75 \mathrm{mg} / \mathrm{m}^{2}$ was administered intravenously on day 2 in both groups of patients. Cycles were repeated every 3 weeks. Before cisplatin administration, patients received intravenous hydration with $1500 \mathrm{~mL}$ of normal saline supplemented with $20 \mathrm{mEq}$ of potassium chloride over 90 minutes followed by $250 \mathrm{~mL}$ of mannitol $20 \%$ solution and $1000 \mathrm{~mL}$ of normal saline, given over 2 hours. Cisplatin infusion was preceded by intravenous administration of a 5-HT3 receptor antagonist plus corticosteroids; prophylactic antiemetic steroids were not routinely administered $\mathrm{d}$ on the day of 
gemcitabine administration. Dose adjustments during the treatment were based on hematologic and non-hematologic toxicities.

In case of grade III toxicities except anemia, alopecia and local toxicities, chemotherapy was held for a maximum of two weeks from the planned d date of $\mathrm{i}$ infusion until resolution to grade $<1$, then given if the patient is medically appropriate with possibility of $25 \%$ dose reduction. If grade IV toxicity occurred, except anemia, the patient was planned to go off protocol 1 . All patients were scheduled to receive at least 2 cycles of therapy, and up to 6 cycles if there was no evidence of disease progression. Treatment was stopped early in cases of patient refusal, severe toxicity, progressive disease (PD), for which they were excluded from being evaluated.

\subsection{Evaluation of Response and Toxicity}

Pretreatment evaluation included the physical examination; ECOG-Performance Status (PS); chest X-ray; brain, thoracic and abdominal computer tomography scan (CT scan); bone scan; electrocardiogram ram; complete blood count $t$ and blood chemistry with liver function tests and creatinine clearance. Response to therapy was assessed for every 2 cycles with CT-based radiological evaluation according to the response evaluation criteria in solid tumors (RECIST) [15]. Patients who finished 6 cycles of chemotherapy were assessed every 2 months. Toxicity was recorded according to the Common Toxicity Criteria of the National Cancer Institute (NCI-CTC, Version 3.0) [16].

\subsection{Statistical Analysis}

The primary objective of our study was to evaluate overall response rate (ORR), and toxicity of the fixed dose rate gemcitabine in comparison to the standard infusion dose rate. Secondary end points were time to determine progression (TTP) and overall survival (OS). Due to the paucity of patients who presented with advanced stage NSCLC to our department, a maximum number of 60 patients could be recruited. This study could be considered as an exploratory study. No sample size was calculated.

Data collected were revised, coded and introduced to the computer system where statistical manipulation and analysis were conducted. The Kaplan Meir survival analysis was used to illustrate the progression free survival and the overall survival. The Chi-squared test was used to compare the overall response rates in both treatment arms.

Hematologic and non-hematologic toxicities were analyzed using the Chi-squared test and the Fisher Exact in case of small number observations. The $p$-value was always set at 0.05 . All statistical analyses were performed using the $15^{\text {th }}$ version of SPSS (Statistical Package for Social Sciences).

\section{Results}

\subsection{Patient and Tumor Characteristics}

From June 2009 to June 2011, a total of 60 patients were enrolled in this trial. Patients' characteristics were balanced between the two arms. Thirty patients were included in each arm. In arm A, the majority of patients were males (90\%), age was below 60 years in $73.3 \%$, PS was $0-1$ in $70 \%$, and $60 \%$ of patients had stage IIIB disease. In arm B, 83.3\% of patients were males, $60 \%$ of patients were below 60 years, PS was 0 - 1 in $63.3 \%$, and $46.7 \%$ had stage IIIB disease. Patients' and tumor characteristics at baseline are listed in Table 1.

\subsection{Response and Survival}

A total of 60 patients were eligible for assessment on intent to treat analysis. The median follow up period was 13 months (range 3 - 24 months). In arm A, only one patient achieved complete response (3.3\%), 43.3 (13 patients) achieved partial response, giving an overall response rate of $46.6 \%, 40 \%$ (12 patients) were stationary, and 13.3\% (4 patients) progressed. The median TTP was 7 months (95\% CI, 6.207 - 7.793 months), median OS time was 12 months (95\% CI, 8.588 - 15.412 months) and 1-year survival was (50\% versus $34 \%, p=0.4$ ). In arm B, complete response was recorded in one patient (3.3\%), 40\% (12 patients) achieved partial response, giving an overall response rate $43.3 \%, 43.3 \%$ (13 patients) were stationary and 13.3\% (4 patients) progressed. The median TTP was 6 months (95\% CI, 4.990 - 7.010 months), median OS time was 11 months (95\% CI, 9.066 12.934 months) (Figure 1) and 1-year survival was 34\% (Figure 2). The difference between the 2 arms of the study, in terms of ORR, TTP, and OS, was statistically non-significant (Table 2). 


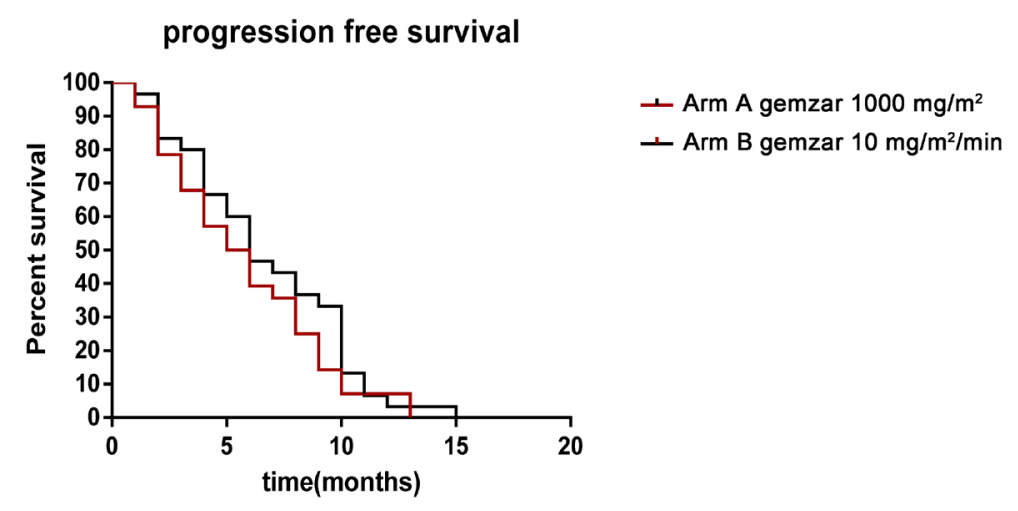

Figure 1. The time to disease progression in both Arm A and B.

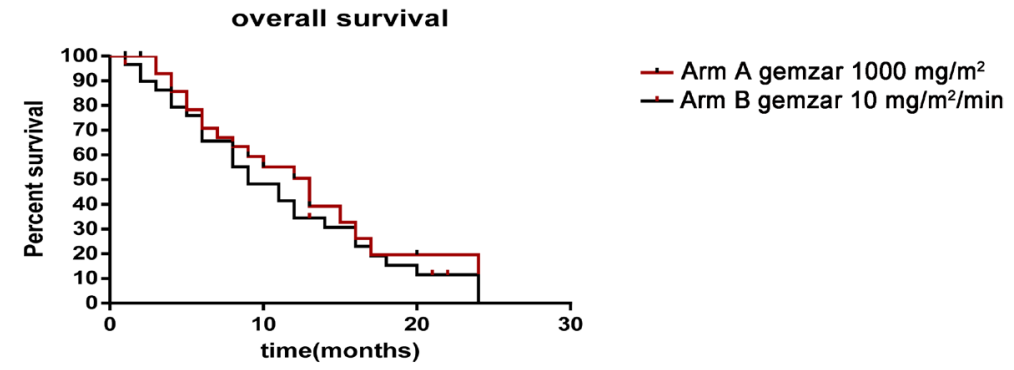

Figure 2. The overall survival in both Arm A and Arm B.

Table 1. Description and comparison between two study groups as regard patient and tumor characteristics.

\begin{tabular}{|c|c|c|c|c|c|}
\hline & & Arm A $(N=30)$ & Arm B $(N=30)$ & $p^{*}$ (Chi square) & Sig. \\
\hline \multirow{2}{*}{ Age Groups } & $<60$ years & 22 (73.3\%) & $18(60 \%)$ & \multirow{2}{*}{0.243} & \multirow[b]{2}{*}{ NS } \\
\hline & $\geq 60$ years & $8(26.7 \%)$ & $12(40.0 \%)$ & & \\
\hline \multirow{2}{*}{ Sex } & Male & 27 (90.0\%) & 25 (83.3\%) & \multirow{2}{*}{0.448} & \multirow{2}{*}{ NS } \\
\hline & Female & $3(10.0 \%)$ & $5(16.7 \%)$ & & \\
\hline \multirow{3}{*}{ Performance status } & 0 & $5(16.7 \%)$ & $8(26.7 \%)$ & \multirow{3}{*}{0.403} & \multirow{3}{*}{ NS } \\
\hline & 1 & $16(53.3 \%)$ & $11(36.7 \%)$ & & \\
\hline & 2 & $9(30.0 \%)$ & $11(36.7 \%)$ & & \\
\hline \multirow[t]{2}{*}{ Pathology } & Squamous & 27 (90\%) & $26(86.7 \%)$ & \multirow[t]{2}{*}{0.707} & \multirow[t]{2}{*}{ NS } \\
\hline & Large cell & $3(10 \%)$ & $4(13.3 \%)$ & & \\
\hline \multirow{2}{*}{ TNM Stage } & IIIB & $18(60 \%)$ & $14(46.7 \%)$ & \multirow{2}{*}{0.301} & \multirow{2}{*}{ NS } \\
\hline & IV & $12(40 \%)$ & $16(53.3 \%)$ & & \\
\hline \multirow{5}{*}{ Site of metastases } & Lung & 7 (23.3\%) & $5(16.7 \%)$ & 0.519 & NS \\
\hline & Bone & $13(43.3 \%)$ & $11(36.7 \%)$ & 0.598 & NS \\
\hline & Liver & 7 (23.3\%) & 5 (16.7\%) & 0.519 & NS \\
\hline & Suprarenal & $3(10 \%)$ & $1(3.3 \%)$ & 0.301 & NS \\
\hline & Scalp & $1(3.3 \%)$ & $0(0.0 \%)$ & 0.313 & NS \\
\hline
\end{tabular}

Table 2. Response to treatment in both arms of the study.

\begin{tabular}{cccc}
\hline Response & Arm A (N = 30) & Arm B (N=30) & $p$ \\
CR & $1(3.3 \%)$ & $1(3.3 \%)$ & \\
PR & $13(43.3 \%)$ & $12(40 \%)$ & 0.994 \\
SD & $12(40 \%)$ & $13(43.3 \%)$ & \\
PD & $4(13.3 \%)$ & $4(13.3 \%)$ & \\
\hline
\end{tabular}




\subsection{Toxicity}

All 60 patients were evaluable for toxicity. No serious adverse events were reported d during the study and none of the patients died from the toxicity. Hematologic toxicities were more prominent in arm B. Main hematological toxicities were neutropenia , mainly grade I and II, observed in $36.7 \%$ and $53.3 \%$ in arm A and B respectively $(p=0.044)$. Grade III neutropenia was equally recorded in $13.3 \%$ in each arm. The incidence of grade I and II anemia was $40 \%$ and $70 \%$ in arm A and B respectively, while grade III anemia was observed in $10 \%$ and $6.7 \%$ in both arms respectively ( $p$ value $=0.024$ ). As regards thrombocytopenia, it was mild in most cases, with grade I and II thrombocytopenia in $23.4 \%$ in arm A and $40 \%$ in arm B. Grade III thrombocytopenia was reported in $3.3 \%$ in each arm. Only one patient (3.3\%) in each arm developed grade IV hematological toxicity, in the form of neutropenia. Non hematologic toxicities were almost comparable in both arms. Grade I and II Nausea and vomiting was observed in $50 \%$ and $46.7 \%$ in arm A and B respectively, while grade III was recorded in $26.7 \%$ and $30 \%$ in both arms respectively. Grade I and II neurotoxicity was noted in $30 \%$ in arm A and in $23.3 \%$ in arm B. The hematologic and non-hematologic toxicities are described in Table 3 and Table 4.

In total, 273 cycles were administered (138 cycles in arm A and 135 cycles in arm B), with a median of 5 cycles per patient (range 2 - 6). Of all the planned infusions, there were 23 dose modifications ( $8.4 \%$ of cycles), 11 dose reductions (4.02\% of cycles) in arm A and 12 dose reduction s (4.39\% of cycles) in arm B, all of them were candidate for chemotherapy dose modification due to encountered toxicities and continue $d$ their planned therapy. Also there was 10 dose omissions (5.2\% of cycles) for gemcitabine, 3 dose omissions (1.56\% of cycles) in arm A and 7 dose omissions (3.46\%) in arm B. Fourteen patients (23.3\% of patients) had cycle delays (7 patients in each arm) for less than 2 months.

\section{Discussion}

Prolonged infusion of gemcitabine at a fixed dose rate (FDR) of $10 \mathrm{mg} / \mathrm{m}^{2}$ per minute, as compared to commonly used 30-minute infusion, has shown promising results in phase I and II clinical trials for the treatment of pancreatic adenocarcinoma [8] and NSCLC [9] [11].

The current phase III randomized clinical trial was conducted to compare the efficacy and tolerability of the standard (arm A) versus the FDR (arm B) infusion of gemcitabine and cisplatin in patients with advanced NSCLC.

Table 3. The hematologic toxicities distribution between Arm A $(n=30)$ and Arm B $(n=30)$.

\begin{tabular}{cccc}
\hline & Neutropenia & Anemia & Thrombocytopenia \\
\hline Grade 1 Arm A & $6 / 30(20 \%)$ & $3 / 30(10 \%)$ & $5 / 30(16.7 \%)$ \\
Arm B & $10 / 30(3.3 \%)$ & $13 / 30(43.3 \%)$ & $8 / 30(26.7 \%)$ \\
Grade 2 Arm A & $5 / 30(16.7 \%)$ & $9 / 30(30 \%)$ & $2 / 30(6.7 \%)$ \\
Arm B & $6 / 30(20 \%)$ & $8 / 30(26.7 \%)$ & $4 / 30(13.3 \%)$ \\
Grade 3 Arm A & $4 / 30(13.3 \%)$ & $3 / 30(10 \%)$ & $1 / 30(3.3 \%)$ \\
Arm B & $4 / 30(13.3 \%)$ & $2 / 30(6.7 \%)$ & $1 / 30(3.3 \%)$ \\
Grade 4 Arm A & $1 / 30(3.3 \%)$ & 0 & 0 \\
Arm B & $1 / 30(3.3 \%)$ & 0 & 0 \\
\hline
\end{tabular}

Table 4. The non-hematologic toxicities distribution between Arm A ( $n=30)$ and $\operatorname{Arm~B~}(n=30)$.

\begin{tabular}{|c|c|c|c|c|c|}
\hline & Nausea and Vomiting & Neurosensory & Mucositis & Renal Toxicity & Fatigue \\
\hline Grade 1 Arm A & 10/30 (33.3\%) & 8/30 (26.7\%) & 2/30 (6.7\%) & $2 / 30(6.7 \%)$ & 10/30 (33.3\%) \\
\hline Arm B & 9/30 (30\%) & $6 / 30(20 \%)$ & $5 / 30(16.7 \%)$ & $3 / 30(10 \%)$ & $7 / 30(23.3 \%)$ \\
\hline Grade 2 Arm A & 5/30 (16.75) & 1/30 (16.7\%) & 1/30 (3.3\%) & 1/30 (3.3\%) & 3/30 (10\%) \\
\hline Arm B & $5 / 30(16.7 \%)$ & $1 / 30(3.3 \%)$ & 0 & 0 & $3 / 30(10 \%)$ \\
\hline Grade 3 Arm A & 8/30 (26.7\%) & 0 & 0 & 0 & 0 \\
\hline Arm B & 9/30 (30\%) & 0 & 0 & 0 & 0 \\
\hline Grade 4 Arm A & 0 & 0 & 0 & 0 & 0 \\
\hline Arm B & 0 & 0 & 0 & 0 & 0 \\
\hline
\end{tabular}


Both treatment arms had almost equal ORR, 46.6\% and 43.3\% in arm A and arm B respectively. In other clinical trials that used FDR infusion of gemcitabine $\left(10 \mathrm{mg} / \mathrm{m}^{2} / \mathrm{min}\right)$, ORR ranged between $20 \%$ and $47 \%$ [9]-[14]. The one-year survival rates in the present study were $50 \%$ versus $34 \%, p=0.4$ in the standard arm and the FDR arm respectively. The median TTP was 7 months and 6 months in both arms respectively, while the median OS time was 12 months and 11 months in the standard arm and the FDR arm respectively. In other similar studies, the one-year survival rates ranged from 36\% to 52\%, median TTP ranged from 4 - 12 months, and median OS ranged between 5 months and 11 months [9]-[14]. The superior results of our study reflects better patients' characteristics, as $60 \%$ and $46.7 \%$ of patients in the standard arm and FDR arm respectively, were stage IIIB disease. In other studies about $80 \%$ of patients were stage IV disease [9] [11]-[14] and enrollment of patients with brain metastases was allowed in four of these trials [9]-[12]. Ceribelli and colleagues included 24\% of patients with brain metastases in their study [9]. In Cappuzzo et al. trial, 66\% of patients were stage IV disease, but they used single agent gemcitabine at a dose of $1500 \mathrm{mg} / \mathrm{m}^{2} \mathrm{~d} 1,8$ every 21 days in both arms [12]. Also, two studies used carboplatin instead of cisplatin [11] [13]. In the trial conducted by Soo et al., they used gemcitabine at a lower dose (750 mg/m² over 75 minutes) in the FDR arm [11].

The equivalent efficacy of both standard 30-min infusion and FDR $10 \mathrm{mg} / \mathrm{m}^{2} / \mathrm{min}$ infusion is in consistence with Qui et al. recently published meta-analysis of six randomized controlled trials, involving 867 patients , which compare d standard rate infusion with FDR infusion in patients with advanced NSCLC [17].

Analysis of toxicity in the current study showed that both schedules were well tolerated and had acceptable toxicity profiles. However, FDR arm was associated with more significant hematologic toxicities, as neutropenia (all grades) was reported in 70\% of patients in the FDR as opposed to 53\% in the standard dose arm. However, GIII-GIV neutropenia was equivalent in both arms at a rate of $16.6 \%$. Anemia (GI-GIII) was recorded in $77 \%$ and 50\% in the FDR arm and the standard arm respectively. Thrombocytopenia was mild and occurred in $43 \%$ and $27 \%$ in the FDR arm and standard arm respectively, however, it was mostly GI-II. Apart from alopecia GI-II, which was more prominent in the FDR arm (47\%) as compared to the standard dose arm (33\%), non-hematologic toxicities were comparable in both arms. Nausea and vomiting GI-III was recorded in $77 \%$ of patients in both arms, while neurotoxicity GI-II was documented in $23.3 \%$ and $30 \%$ of patients in the FDR arm and standard infusion arm respectively. These findings are in agreement with previous reports that gemcitabine infusion over a prolonged time is usually associated with increased hematologic toxicities [8] [18] [19]. Also, our results are consistent with Qiu et al. meta-analysis, in which FDR infusion was associated with more Grade III-IV hematologic and non-hematologic toxicities [17]. Previous studies in NSCLC that investigated ted gemcitabine/cisplatin regimens with FDR gemcitabine reported GIII-IV neutropenia in the range of $15 \%$ - 26\% in the standard arm as compared to 30\% - 395\% in the FDR arm, GIII-IV thrombocytopenia in the range of 3\% - 19\% in the standard arm and 13\% - 18\% in the FDR arm, while GIII-IV anemia ranged between $2 \%$ - $8 \%$ in the standard arm and 11\% - 13\% in the FDR arm [9] [12] [14]. Other regimens that used carboplatin instead of cisplatin had more severe GIII-IV hematologic toxicities [11]-[13].

\section{Conclusion}

FDR administration of gemcitabine in combination with cisplatin had equivalent efficacy to the standard 30min gemcitabine infusion with cisplatin in patients with advanced NSCLC. However, the FDR infusion protocol was associated with more severe hematologic toxicities and its administration in elderly patients or those with poor performance status should be with caution. Further studies are recommended to evaluate different infusion protocols of gemcitabine particularly in the elderly patients above 65 years who represent more than $50 \%$ of all patients with NSCLC at diagnosis. The low-dose prolonged infusion of gemcitabine at a dose of $250 \mathrm{mg} / \mathrm{m}^{2}$ over 6 hours showed promising results in treatment of NSCLC.

\section{References}

[1] Siegel, R.L., Naishadham, D. and Jamal, A. (2012) Cancer Statistics. CA: A Cancer Journal for Clinicians, 62, 10-29. http://dx.doi.org/10.3322/caac.20138

[2] Ferlay, J., Shin, H.R., Bary, F., et al. (2010) GLOBOCAN 2008 v2.0, Cancer Incidence and Mortality Worldwide: IARC Cancer Base No. 10. International Agency for Research on Cancer, Lyon. http://globocan.iarc.fr/

[3] Greene, F.L., Page, D.L., Fleming, I.D., Firtz, A., Balch, D.G. and Haller, M.M. (2002) AJCC Cancer Staging Manual. 
6th Edition, Springer-Verlag, Berlin/Heidelberg/New York/London/Paris/Tokyo/Hong Kong, 435.

[4] Arriagada, R., Auperin, A., Burdett, S., Higgins, J.P., Johnson, D.H., Le Chevalier, T., Le Pechoux, C., Pamar, M.K., Pignon, P.J., Souhami, R.L., Stephens, R.J., Stewart, L.A., Tierney, J.F., Tribodet, H. and van Meerbeeck, J., On Behalf of the NSCLC Meta-Analyses Collaborative Group (2010) Adjuvant Chemotherapy with or witout Postoperative Radiotherapy in Operable Non-Small-Cell Lung Cancer: Two Meta-Analyses of Individual Patient Data. Lancet, 375, 1267-1277. http://dx.doi.org/10.1016/S0140-6736(10)60059-1

[5] Scagliotti, G.V., De Marinis, F., Rinaldi, M., Crino, L., Gridelli, C., Ricci, S., Matano, E., Boni, C., Marangolo, M., Failla, G., Altavilla, G., Adamo, V., Ceribelli, A., Clerici, M., Di Costanzo, F., Frontini, L. and Tona, M. (2002) Phase III Randomized Trial Comparing Three Platinum-Based Doublets in Advanced Non-Small Cell Lung M. Cancer Italian Lung Cancer Project. Journal of Clinical Oncology, 20, 4285-4291. http://dx.doi.org/10.1200/JCO.2002.02.068

[6] Pastor-Anglada, M., Molina-Arcas, M., Casado, F.J., Bellosillo, B., Colomer, D. and Gil, J. (2004) Nucleoside Transporters in Chronic Lymphocytic Leukemia. Leukemia, 18, 385-393. http://dx.doi.org/10.1038/sj.leu.2403271

[7] Abratt, R.P., Bezwoda, W.R., Falkson, G., Goedhals, L., Hacking, D. and Rugg, T.A. (1994) Efficacy and Safety Profile of Gemcitabine in Non-Small-Cell Lung Cancer: A Phase II Study. Journal of Clinical Oncology, 12, 1535-1540.

[8] Tempero, M., Plunkett, W., Ruiz Van Haperen, V., Hainsworth, J., Lenzi, R. and Abbruzzese, J. (2003) Randomized Phase II Comparison of Dose-Intense Gemcitabine: Thirty-Minute Infusion and Fixed Dose Rate Infusion in Patients with Pancreatic Adenocarcinoma. Journal of Clinical Oncology, 21, 3402-3408. http://dx.doi.org/10.1200/JCO.2003.09.140

[9] Ceribelli, A., Gridelli, C., De Marinis, F., Fabi, A., Gamucci, T., Cortesi, E., Barduagni, M., Antimi, M., Maione, P., Migliorino, M.R., Giannarelli, D. and Cognetti, F. (2003) Prolonged Gemcitabine Infusion in Advanced Non-Small Cell Lung Carcinoma: A Randomized Phase II Study of Two Different Schedules in Combination with Cisplatin. Cancer, 98, 337-343. http://dx.doi.org/10.1002/cncr.11501

[10] Cappuzzo, F., Novello, S., De Marinis, F., Selvaggi, G., Scagliotti, G.V., Barbieri F., Maur, M., Papi, M., Bartolini, S., Marini, L. and Crino, L. (2006) A Randomized Phase II Trial Evaluating Standard (50 mg/min) versus Low (10 $\mathrm{mg} / \mathrm{min}$ ) Infusion Duration of Gemcitabine as First-Line Treatment in Advanced Non-Small-Cell Lung Cancer Patients Who Are Not Eligible for Platinum-Based Chemotherapy. Lung Cancer, 52, 319-325. http://dx.doi.org/10.1016/j.lungcan.2006.03.004

[11] Soo, R.A., Wang, L.Z., Tham, L.S., Yong, W.P., Boyer, M., Lim, H.L., Lee, H.S., Millward, M., Liang, S., Beale, P., Lee, S.C. and Goh, B.C. (2006) A Multicenter Randomized Phase II Study of Carboplatin in Combination to Gemcitabine at Standard Rate or Fixed Dose Rate Infusion in Patients with Advanced Stage Non-Small-Cell Lung Cancer. Annals of Oncology, 17, 128-133. http://dx.doi.org/10.1093/annonc/mdl084

[12] Gridelli, C., Gallo, C., Ceribelli, A., Gebbia, V., Gamucci, T., Ciardiello, F., Carozza, F., Favaretto, A., Daniele, B., Galetta, D., Barbera, S., Rosette, F., Rossi, A., Maione, P., Cognetti, F., Testa, A., Di Maio, M., Morabito, A., Perrone, F. and GECO Investigators (2007) Factorial Phase III Randomized Trial of Rofecoxib and Prolonged Constant Infusion of Gemcitabine in Advanced Non-Small-Cell Lung Cancer: The GEmcitabine-COxib in NSCLC (GECO) Study. Lancet Oncology, 8, 500-512. http://dx.doi.org/10.1016/S1470-2045(07)70146-8

[13] Wang, L.R., Huang, M.Z., Zhang, G.B., Xu, N. and Wu, X.H. (2007) Phase II Study of Gemcitabine and Carboplatin in Patients with Advanced Non-Small-Cell Lung Cancer. Cancer Chemotherapy and Pharmacology, 60, 601-607. http://dx.doi.org/10.1007/s00280-007-0504-X

[14] Pereira, J.R., Fein, L., Del Giglio, A., Blajman, C.R., Richardet, E., Schwartsmann, G., Orlando, M., Hall, B.J., West, T.M. and van Kooten, M. (2007) Gemcitabine Administered as a Short Infusion versus a Fixed Dose Rate in Combination with Cisplatin for the Treatment of Patients with Advanced Non-Small Cell Lung Cancer. Lung Cancer, 58, 80-87. http://dx.doi.org/10.1016/j.lungcan.2007.05.004

[15] Therasse, P., Arbuck, S.G., Eisenhauer, E.A., Wanders, J., Kaplan, R.S., Rubinstein, L., Verweij, J., Van Glabbeke, M., van Oosterom, A.T., Christian, M.C. and Gwyther, S.G. (2000) New Guidelines to Evaluate the Response to Treatment in Solid Tumors: European Organization for Research and Treatment of Cancer, National Cancer Institute of the United States, National Cancer Institute of Canada. Journal of the National Cancer Institute, 92, 205-216. http://dx.doi.org/10.1093/jnci/92.3.205

[16] (2003) Cancer Therapy Evaluation Program, Common Terminology Criteria for Adverse Events, Version 3.0, DCTD, NCI, NIH, DHHS. http://cte b.cancer.gov

[17] Qui, M.T., Ding, X.X., Hu, J.W., Tian, H.Y., Yin, R. and Xu, L. (2012) Fixed-Dose Rate Infusion and Standard Rate Infusion of Gemcitabine in Patients with Advanced Non-Small-Cell Lung Cancer: A Meta-Analysis of Six Trials. Cancer Chemotherapy and Pharmacology, 70, 861-873. http://dx.doi.org/10.1007/s00280-012-1974-Z

[18] Xu, N., Shen, P., Zhang, X.C., Yu, L.F., Bao, H.Y., Shi, G.M., Huanq, S., Chen, J., Mou, H.B. and Fang, W.J. (2007) Phase II Trial of a 2-h Infusion of Gemcitabine plus Carboplatin as First-Line Chemotherapy for Advanced NonSmall-Cell Lung Cancer. Cancer Chemotherapy and Pharmacology, 59, 1-7. 
http://dx.doi.org/10.1007/s00280-006-0237-2

[19] Tibaldi, C., Bernardini, I., Chella, A., Russo, F., Toma, G., Tempestini, F., Malventi, M., Vasile, E, Ambrosino, N. and Falcone, A. (2006) Prolonged Gemcitabine Infusion in Advanced Non-Small-Cell Lung Cancer with Stable Disease after Gemcitabine 30-Min Infusion. Lung Cancer, 51, 217-223. http://dx.doi.org/10.1016/j.lungcan.2005.10.013 
Scientific Research Publishing (SCIRP) is one of the largest Open Access journal publishers. It is currently publishing more than 200 open access, online, peer-reviewed journals covering a wide range of academic disciplines. SCIRP serves the worldwide academic communities and contributes to the progress and application of science with its publication.

Other selected journals from SCIRP are listed as below. Submit your manuscript to us via either submit@scirp.org or Online Submission Portal.
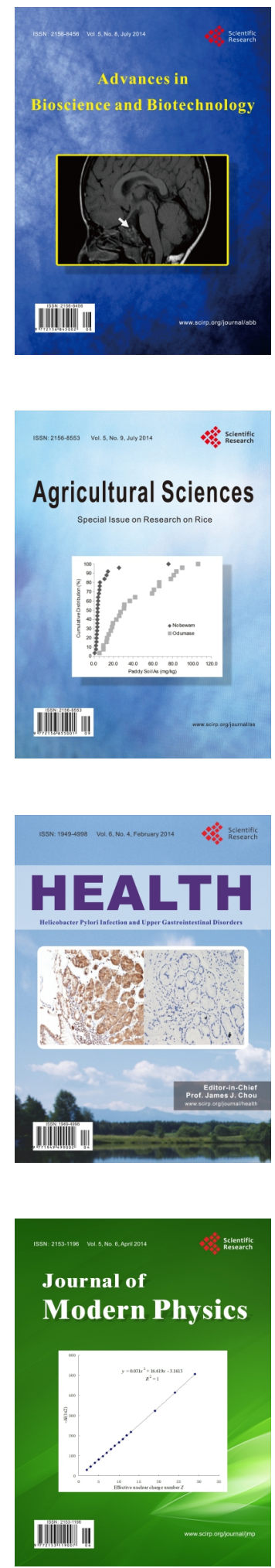
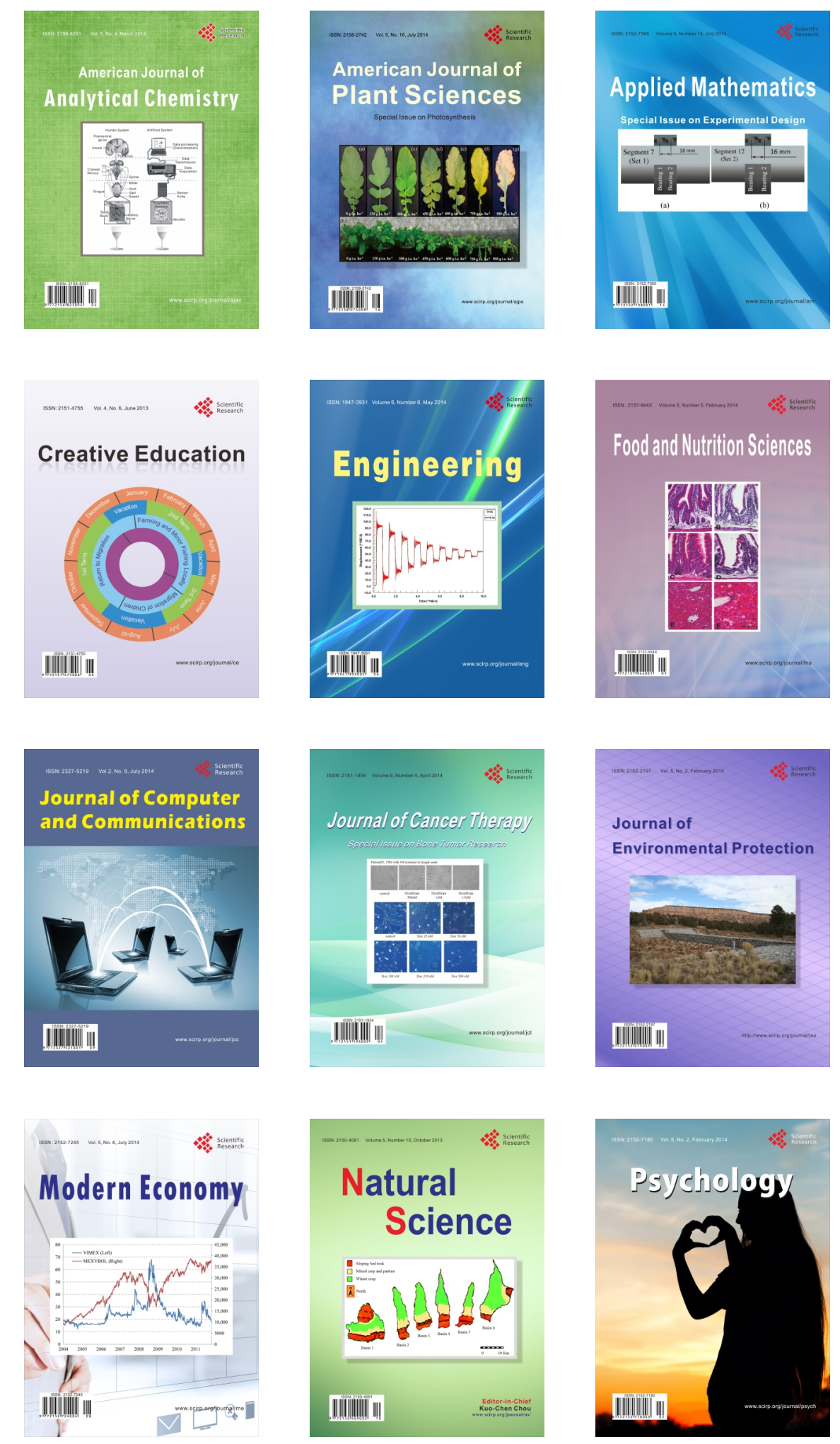